\title{
Thorium, Uranium and Rare Earth Elements Concentration in Weathered Japanese Soil Samples
}

\author{
Sarata Kumar SAHOO*, Masahiro HOSODA, Sadatoshi KAMAGATA, Atsuyuki SORIMACHI, Tetsuo ISHIKAWA, \\ Shinji TOKONAMI, Shigeo UCHIDA
}

Research Centre for Radiation Protection, National Institute of Radiological Sciences, 4-9-1 Anagawa, Inage-ku, Chiba, 263-8555, Japan

\begin{abstract}
The geochemical behavior of thorium, uranium and rare earth elements (REEs) are relatively close to one another while compared to other elements in a geological environment. Radioactive elements like ${ }^{232} \mathrm{Th}$ and ${ }^{238} \mathrm{U}$ along with their decay products (e.g. ${ }^{226} \mathrm{Ra}$ ) are present in most environmental matrices and can be transferred to living bodies by different pathways which can lead to the sources of exposure to man. For these reasons, it has been necessary to monitor those natural radionuclides in weathered soil samples to assess the possible hazards. It has been observed that granitic rocks contain higher amounts of $\mathrm{U}$, Th and light REEs compared to other igneous rocks such as basalt and andesites. To better understand the interaction between REEs and soils, the nature of soils must be considered. In this paper, we discussed the distribution pattern of ${ }^{232} \mathrm{Th}$ and ${ }^{238} \mathrm{U}$ along with REEs in soil samples of weathered acid rock (granite and ryolite) collected from two prefectures of Japan: (1) Kobe city in Hyogo prefecture and (2) Mutsu city and Higashidori village in Aomori prefecture.
\end{abstract}

KEYWORDS: uranium, thorium, rare earth elements, weathered soil,

\section{Introduction}

In recent years, attention has been drawn to the development and steady introduction of analytical methods suitable for quantification of thorium and uranium tracers. From the viewpoint of radiation protection, determination of natural radionuclides such as $\mathrm{U}$ and $\mathrm{Th}$ in soil samples are also important. It has been observed that granitic rocks contain higher amounts of $\mathrm{Th}, \mathrm{U}$ and light rare earth elements (REEs) compared to other igneous rocks such as basalt and andesites. ${ }^{1,2)}$ REE appear as natural trace metals in the whole geosphere and have become important geochemical tracers during last few decades. ${ }^{3,4}$ Some REE isotopes also occur as radionuclides in the decay series of nuclear fission and can therefore be found in nuclear waste or be released by nuclear accidents. Therefore, determination of REEs in soil samples has become important to obtain REE profiles in order to foretell any possible environmental effects.

The aim of the present study is to characterise the background levels of Th, U and REEs in weathered soil samples from two prefectures of Japan i.e. Kobe city and Mutsu city and Higashidori village in Aomori prefecture. The specific activities of ${ }^{232} \mathrm{Th}$ and ${ }^{238} \mathrm{U}$ in soil samples were measured using a high-purity germanium detector (HP Ge) and compared with inductively coupled plasma mass spectrometry (ICP-MS).

\section{Experiments}

\section{Sample collections}

The study areas (Fig.1) were selected based on weathered

*Corresponding Author, E-mail: sahoo@nirs.go.jp

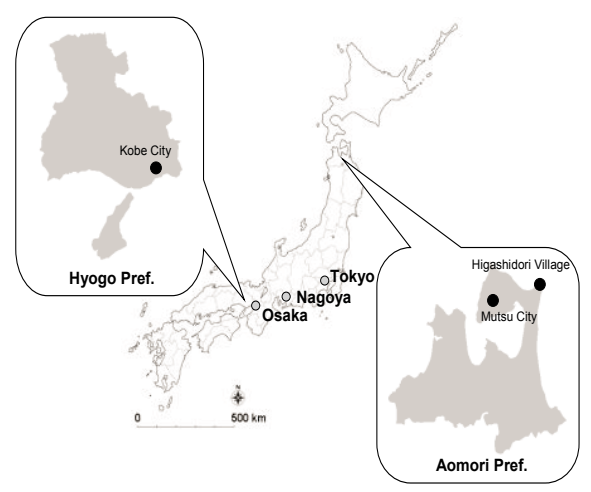

Fig. 1 Map showing sampling sites

acid rock areas (granite and ryholite) referring the geological map of Japan. We have collected surface soil samples $(0-10 \mathrm{~cm})$ as well as up to $50 \mathrm{~cm}$ depth profile studies from three locations where radon/thoron exhalation rates were simultaneously measured. In this study, we have selected two areas of different climates e.g. Kobe city, Hyogo prefecture (seven samples) and Aomori prefecture (Mutsu city: three samples) and Higashidori village (four samples). Location of soil samples with certain soil parameters have been summarized in Table 1. Though radon/thoron exhalation rates were obtained from the same locations on seasonal basis, we have carried out chemical analyses of $\mathrm{Th}$, $\mathrm{U}$ and REEs once from the soil samples.

\section{Sample preparation and measurement for gamma spectrometry}

All samples (about $100 \mathrm{gm}$ ) were crushed to a fine powder form. Later samples were placed in U8 standard cylindrical containers (diameter $=48 \mathrm{~mm} ; \mathrm{h}=58 \mathrm{~mm}$ ). They were sealed using adhesive in order to avoid any possibility 
of out-gassing of radon or thoron.

Table 1 Location of soil samples

\begin{tabular}{|c|c|c|c|}
\hline Sample ID & Location & $\begin{array}{c}\text { Volumetric } \\
\text { Moisture } \\
\text { content }\left(\mathrm{m}^{3} \mathrm{~m}^{-3}\right)\end{array}$ & $\begin{array}{l}\text { Dose rate } \\
\left(\text { nGy h }^{-1}\right)\end{array}$ \\
\hline Kobe 1 & $\begin{array}{c}34^{\circ} 44^{\prime} \mathrm{N} \\
135^{\circ} 17^{\prime} \mathrm{E}\end{array}$ & $0.155 \pm 0.021$ & $46 \pm 11$ \\
\hline Kobe 2 & $\begin{array}{l}34^{\circ} 44^{\prime} \mathrm{N} \\
135^{\circ} 17^{\prime} \mathrm{N}\end{array}$ & $0.172 \pm 0.020$ & $81 \pm 13$ \\
\hline Kobe 3 & $\begin{array}{c}34^{\circ} 44^{\prime} \mathrm{N} \\
135^{\circ} 17^{\prime} \mathrm{E}\end{array}$ & $0.260 \pm 0.031$ & $90 \pm 13$ \\
\hline Kobe 4 & $\begin{array}{l}34^{\circ} 43^{\prime} \mathrm{N} \\
135^{\circ} 17^{\prime} \mathrm{E}\end{array}$ & $0.139 \pm 0.015$ & $110 \pm 18$ \\
\hline Kobe 5 & $\begin{array}{l}34^{\circ} 43^{\prime} \mathrm{N} \\
135^{\circ} 17^{\prime} \mathrm{E}\end{array}$ & $0.097 \pm 0.007$ & $92 \pm 8.5$ \\
\hline Kobe 6 & $\begin{array}{l}34^{\circ} 43^{\prime} \mathrm{N} \\
135^{\circ} 17^{\prime} \mathrm{E}\end{array}$ & $0.143 \pm 0.019$ & $99 \pm 11$ \\
\hline Kobe 7 & $\begin{array}{l}34^{\circ} 43^{\prime} \mathrm{N} \\
135^{\circ} 17^{\prime} \mathrm{E}\end{array}$ & $0.152 \pm 0.076$ & $86 \pm 21$ \\
\hline Mutsu 1 & $\begin{array}{l}41^{\circ} 10^{\prime} \mathrm{N} \\
140^{\circ} 53^{\prime} \mathrm{E}\end{array}$ & $0.138 \pm 0.038$ & $59 \pm 8.4$ \\
\hline Mutsu 2 & $\begin{array}{c}41^{\circ} 9^{\prime} \mathrm{N} \\
140^{\circ} 53^{\prime} \mathrm{E}\end{array}$ & $0.337 \pm 0.059$ & $44 \pm 3.9$ \\
\hline Mutsu 3 & $\begin{array}{l}41^{\circ} 14^{\prime} \mathrm{N} \\
140^{\circ} 59^{\prime} \mathrm{E}\end{array}$ & $0.257 \pm 0.035$ & $35 \pm 6.3$ \\
\hline $\begin{array}{l}\text { Higashidori } \\
\text { Village } 1\end{array}$ & $\begin{array}{l}41^{\circ} 25^{\prime} \mathrm{N} \\
141^{\circ} 27^{\prime} \mathrm{E}\end{array}$ & $0.159 \pm 0.040$ & $36 \pm 6.4$ \\
\hline $\begin{array}{l}\text { Higashidori } \\
\text { Village } 2\end{array}$ & $\begin{array}{l}41^{\circ} 25^{\prime} \mathrm{N} \\
141^{\circ} 27^{\prime} \mathrm{E}\end{array}$ & $0.326 \pm 0.050$ & $55 \pm 5.3$ \\
\hline $\begin{array}{l}\text { Higashidori } \\
\text { Village } 3\end{array}$ & $\begin{array}{l}41^{\circ} 25^{\prime} \mathrm{N} \\
141^{\circ} 27^{\prime} \mathrm{E}\end{array}$ & $0.202 \pm 0.060$ & $40 \pm 3.7$ \\
\hline $\begin{array}{l}\text { Higashidori } \\
\text { Village } 4\end{array}$ & $\begin{array}{l}41^{\circ} 25^{\prime} \mathrm{N} \\
141^{\circ} 27^{\prime} \mathrm{E}\end{array}$ & $0.149 \pm 0.040$ & $34 \pm 4.0$ \\
\hline
\end{tabular}

The sealed samples were kept for about 30 days (equivalent to 7 half-lives of ${ }^{222} \mathrm{Rn}$ ) in order that ${ }^{226} \mathrm{Ra}$ and ${ }^{222} \mathrm{Rn}\left(\mathrm{t}_{1 / 2}=3.8 \mathrm{~d}\right)$ and its short-lived gamma emitting decay products, ${ }^{214} \mathrm{Bi}$ and ${ }^{214} \mathrm{~Pb}$ attained secular equilibrium in sealed containers. ${ }^{228} \mathrm{Ra}$ and ${ }^{228} \mathrm{Th}$ will also have attained secular equilibrium with its gamma emitting decay products.

The specific activity of ${ }^{226} \mathrm{Ra},{ }^{232} \mathrm{Th}$ were measured using a high purity germanium detector (ORTEC GEM-100210) $\gamma$-spectroscopy coupled with a 16k multi-channel analyzer (ORTEC, 7700-010) with a range 0-4000 keV and computer software Gamma Studio (Seiko EG \& G, 2000) for gamma-ray spectral analysis. The detector efficiency was determined using a $100 \mathrm{~g}$ multi-nuclide standard source supplied by Japan Radioisotope Association with quoted gamma energies ranging from 60 to $1333 \mathrm{keV}$ an overall uncertainty of less than $5 \%$. The results were compared with a natural soil standard IAEA-375 to check the reproducibility of the method. The counting time was pre-set at $80,000 \mathrm{sec}$. The gamma emitting decay products, ${ }^{214} \mathrm{~Pb}(295.2 \mathrm{keV})$, ${ }^{214} \mathrm{~Pb} \quad(351.9 \mathrm{keV})$ and ${ }^{214} \mathrm{Bi}(609.3 . \mathrm{keV})$ in secular equilibrium in about 30 days with ${ }^{226} \mathrm{Ra},{ }^{228} \mathrm{Ac}(911.2 \mathrm{keV})$ with ${ }^{228} \mathrm{Ra},{ }^{212} \mathrm{~Pb}(238.6 \mathrm{keV})$ and ${ }^{212} \mathrm{Bi}$ [mean of ${ }^{208} \mathrm{Tl}(583.2$ $\mathrm{keV})$, and ${ }^{208} \mathrm{Tl}(2614.53 \mathrm{keV})$ divided by branching ratio of 0.36 ] with ${ }^{228} \mathrm{Th}$, and ${ }^{40} \mathrm{~K}$ gamma (1461 keV), were counted simultaneously. The data for radionuclide gamma energy and branching ratio were taken from the Table of Isotopes (Firestone 1996). ${ }^{5)}$

\section{Sample preparation and measurement by ICP-MS analysis}

About $250 \mathrm{mg}$ of each sample was digested with a mixture of high purity nitric, hydrofluoric and perchloric acids (Tama Chemicals, Japan) using a microwave unit (Milestone Ethos-1600, Italy). A reference material, JLK-1 lake sediment sample, supplied by the Geological Survey of Japan (GSJ) was digested with the same acid proportions and analyzed for quality control and a blank sample with the same mixture of acids was processed with each batch of samples.

The ICP-MS instrument used was an Agilent 7500 (Agilent Technologies, Tokyo, Japan). Prior to ICP-MS analyses, standard solutions were prepared from SPEX multi-element plasma standard (Spex CertiPrep, NJ, USA) at $0,100,250,500,1000 \mathrm{ppt}$ to derive calibration curves. Concentration of $\mathrm{Th}, \mathrm{U}$ and REEs were measured from standard solutions, reference material, blank and soil samples. ${ }^{6,7)}$

\section{Results and Discussions}

\section{Comparison between two measurement methods}

The specific activity of ${ }^{238} \mathrm{U}$ is assumed to be same as that of ${ }^{226} \mathrm{Ra}$. Analytical results obtained using ICP-MS for Th and $U$ were compared with $\gamma$-ray counting. The measurement of ${ }^{232} \mathrm{Th}$ showed a good agreement between both methods with a correlation coefficient of $\mathrm{R}^{2}=0.91$, as shown in Fig. 2 . Similarly, ${ }^{238} \mathrm{U}$ with the HPGe detector and ICP-MS shows a good agreement with a co-efficient of $\mathrm{R}^{2}=0.84$ as shown in Fig. 3. Therefore both analytical techniques are suitable to measure trace amounts of radioactive elements in soil samples. However, ICP-MS method is rapid and can detect elements of our interest. 
The specific activity of ${ }^{226} \mathrm{Ra},{ }^{232} \mathrm{Th}$ and ${ }^{40} \mathrm{~K}$ in the samples are as follows: (1) ${ }^{226} \mathrm{Ra}: 6.7 \pm 0.4 \mathrm{~Bq} \mathrm{~kg}^{-1}$ to $35.6 \pm 0.6 \mathrm{~Bq}$ $\mathrm{kg}^{-1}$ with a mean of $18.1 \pm 0.7 \mathrm{~Bq} \mathrm{~kg}^{-1}$, (2) ${ }^{232} \mathrm{Th}: 8.6 \pm 0.4$ to $59.1 \pm 1.1 \mathrm{~Bq} \mathrm{~kg}^{-1}$ with a mean of $25.92 \pm 1.0 \mathrm{~Bq} \mathrm{~kg}^{-1}$ and

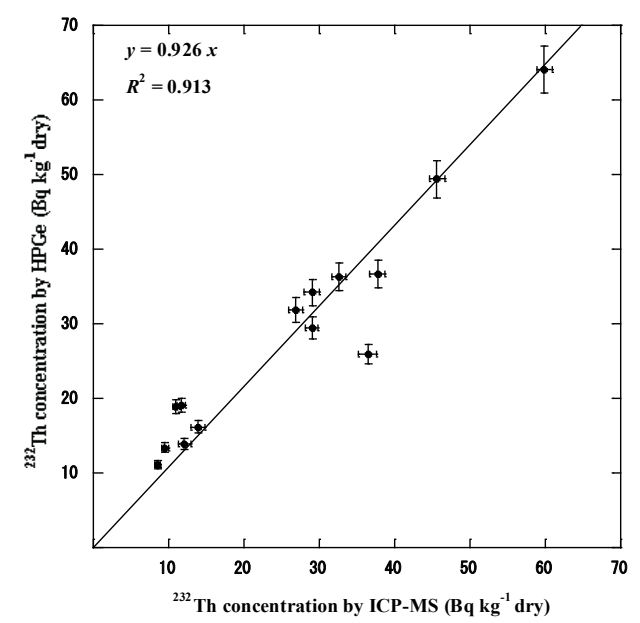

Fig. 2 Correlation between the measurement of ${ }^{232}$ Th using ICP-MS and $\gamma$-spectroscopy

(3) ${ }^{40} \mathrm{~K}: 136.2 \pm 2.7 \mathrm{~Bq} \mathrm{~kg}^{-1}$ to $852.8 \pm 6.5 \mathrm{~Bq} \mathrm{~kg}^{-1}$ with a mean of $535.6 \pm 3.2 \mathrm{~Bq} \mathrm{~kg}^{-1}$. Most of these values of soil samples are less than world average values as reported by UNSCEAR report. ${ }^{8)}$ The specific radionuclide concentrations were relatively higher for Kobe samples in comparison to Higashidori village of Aomori prefecture. However, uranium concentration in these soil samples are comparable to earlier reports. ${ }^{7,9)}$

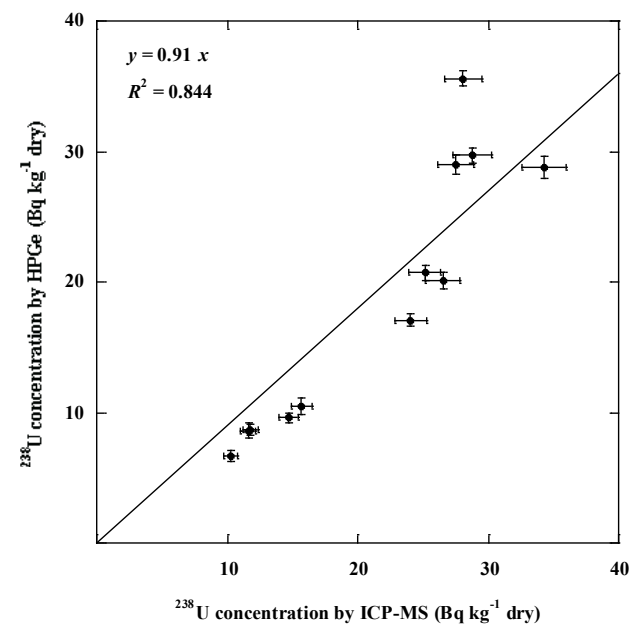

Fig. 3 Correlation between the measurement of ${ }^{238} \mathrm{U}$ using ICP-MS and $\gamma$-spectroscopy

\section{Depth profile studies of Kobe Soil}

Soils are regarded as the main source of radon. Therefore, we collected soil samples in a few selected sites of Kobe to check the variation of uranium concentration up to a depth of $50 \mathrm{~cm}$ using a core sampler and have been divided into $0-10$,
10-20, 30-40 and 40-50 cm. The uranium concentrations varied as follows: (1) Kobe-1: surface layer with $0.93 \mu \mathrm{g} \mathrm{g}^{-1}$ and 20-30 $\mathrm{cm}$ layer with $0.88 \mu \mathrm{g} \mathrm{g}^{-1}$ (2) Kobe-2: $2.01 \mu \mathrm{g} \mathrm{g}^{-1}$ was for the surface layer and $2.22 \mu \mathrm{g} \mathrm{g}^{-1}$ was found for 20-30 $\mathrm{cm}$ layer, and (3) Kobe 3: Surface layer was $2.21 \mu \mathrm{g} \mathrm{g}^{-1}$ and for the deepest layer $40-50 \mathrm{~cm}$ was $2.76 \mu \mathrm{g} \mathrm{g}^{-1}$. There was no significant variation observed with depth profile studies as can be noticed in Fig. 4. There was less than 5\% variation in a particular core sample. The concentrations of $U$ and Th determined by ICP-MS are summarized in Table 2. The $\mathrm{U} / \mathrm{Th}$ ratio varies between 0.2 to 0.3 and can be comparable to continental crust. ${ }^{10)}$

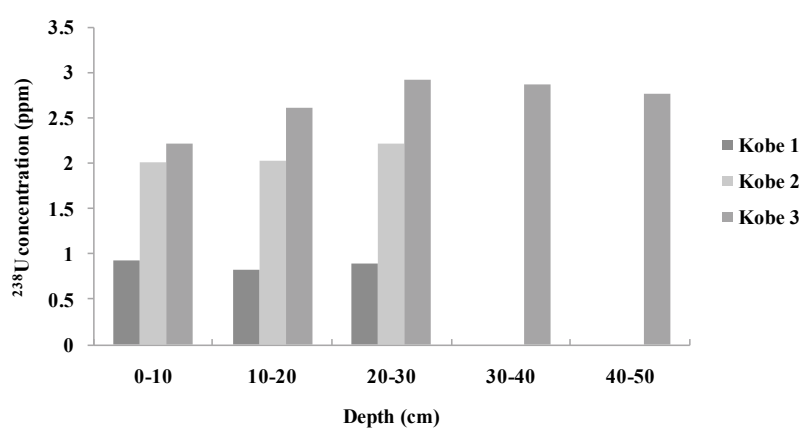

Fig. 4 Depth profile studies of soil samples

Table 2 Concentration $\left(\mu \mathrm{g} \mathrm{g}^{-1}\right)$ of Th and $\mathrm{U}$ in soil samples measured by ICP-MS

\begin{tabular}{lcc}
\hline \multicolumn{1}{c}{ Location } & Th & U \\
\hline Kobe 1 & 3.42 & 0.93 \\
Kobe 2 & 8.42 & 2.01 \\
Kobe 3 & 9.04 & 2.21 \\
Kobe 4 & 15.77 & 2.25 \\
Kobe 5 & 7.24 & 1.93 \\
Kobe 6 & 12.16 & 2.31 \\
Kobe 7 & 8.95 & 2.13 \\
Mutsu 1 & 3.74 & 0.93 \\
Mutsu 2 & 6.36 & 2.75 \\
Mutsu 3 & 3.98 & 1.26 \\
Higashidori 1 & 4.65 & 0.94 \\
Higashiori 2 & 7.84 & 2.74 \\
Higashidori 3 & 4.69 & 1.18 \\
Higashidori 4 & 3.31 & 0.82 \\
\hline
\end{tabular}

\section{REEs in soil samples}

The determination of REEs in geological samples is extremely important in earth science studies because their chemical behaviour is governed by the systematic contraction of trivalent ionic radii with atomic number as the shielded electrons are added to the inner $4 \mathrm{f}$ shell and some of the elements, especially $\mathrm{Ce}$ and $\mathrm{Eu}$ occur in oxidation states other than +3 , the main oxidation state of the group. We have measured REEs from the soil samples using ICP-MS. 
Sample preparation can be a major problem with REE analysis as the bulk of these elements and particularly the heavier REEs (Dy-Lu), commonly resides in refractory accessory minerals such as zircon, sphene and garnet phases. In this study, microwave digestion was successfully used for complete dissolution of sample. We have selected two samples from Kobe and one each from Mutsu and Higashidori village to check the REE pattern of soil samples. REE data obtained by certified and measured values obtained for standard reference materials. The precision by ICP-MS achieved is better than $5 \%$ RSD with a comparable accuracy.

The concentration of Th, U and REEs, measured (from $<0.1$ upto a few $\mu \mathrm{g} \mathrm{l}^{-1}$ ) are 1 2 order of magnitude less than the chondrites, in agreement with concentration of the elements. Chondrititic meteorites are chosen for normalization as they are thought to be relatively unfractionated samples of the solar system dating from the original nucleosynthesis. Leedy chondrite normalized patterns are shown in Fig. 5 which allows a better insight into geological processes. ${ }^{11)}$ The REEs exhibit light REE-enriched patterns when normalized to chondrite which indicates that the REEs are taken up in proportion to their relative concentration in the source rocks or heavy REEs are preferentially mobilised. There are no significant variation in the concentration of REEs, $U$ and Th related to general location within the study area which may be reflective of one type of source in the concentration of these elements in the reservoir rocks at depth.

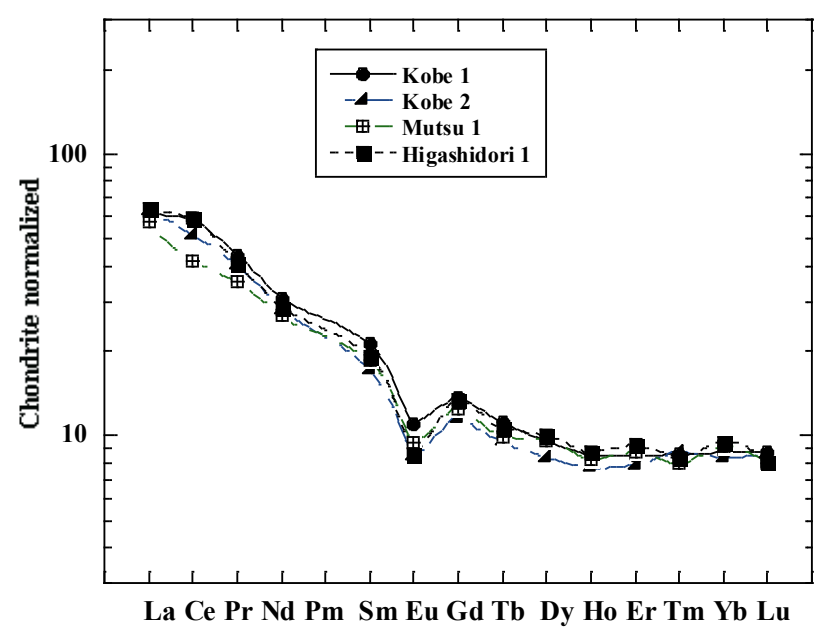

Fig. 5 Leedy chondrite normalized REE pattern of Soils

Negative Eu anomaly was noticed in soil samples and chiefly controlled by feldspars, particularly in felsic magmas, for $\mathrm{Eu}$ (+2 oxidation state) is compatible in plagioclase and potassium feldspars, in contrast to the trivalent REE which are incompatible. Thus the removal of feldspar from a felsic melt by crystal fractionation or the partial melting of a rock in which feldspar is retained in the source will give rise to a negative Eu anomaly in the melt. Ce anomaly is not so much evident which can be explained by the redox behaviour of $\mathrm{Ce}$ by contrast with the other REEs, occur in both trivalent and tetravalent state. Ce appears at the surface as Ce (IV) in $\mathrm{CeO}_{2}$. This oxide is less soluble than the other REE oxides and consequently, Ce will be depleted with respect to other REE in deeper part of soil. This can be attributed to the fact that REEs in soil come mainly from minerals inherent in soil and are not influenced by environmental conditions.

\section{Conclusion}

ICP-MS is currently playing a leading role in the analysis of Th, $U$ and REEs and has proven to be a powerful technique for handling routine analytical problems involving both elemental and isotopic analysis. Soil samples analysed in both prefecture, appear to be of same geological origin.

\section{Acknowledgment}

This work has been supported by the Agency for Natural Resources and Energy, The Ministry of Economy, Trade and Industry (METI), Japan.

\section{References}

1) J. J. W. Rogers, A.S. Adams, Thorium, Handbook of Geochemistry, Ed. K.H. Wedepohl, Vol. II/5, Springer-Verlag, Berlin, 90-E (1969)

2) J. J. W. Rogers, A.S. Adams, Uranium, Handbook of Geochemistry, Ed. K.H. Wedepohl, Vol. II/5, Springer-Verlag, Berlin, 92-E (1969)

3) P. Henderson, Rare Earth Element Geochemistry, Elsevier Science Publishers, B.V., Amsterdam (1984).

4) S. M. McLennan, Rare earth element geochemistry and the "tetrad" effect, Geochim. Cosmochim. Acta, 58 (1994) 2025.

5) R. B. Firestone, Table of Isotopes, $8^{\text {th }}$ Edition, John Wiley \& Sons, New York, 1996.

6) S. K. Sahoo, H. Yonehara, K. Kurotaki, K. Shiraishi, V. Ramzaev, A. Barkovski, Determination of rare earth elements, thorium and uranium by inductively coupled plasma mass spectrometry and strontium isotopes by thermal ionization mass spectrometry in soil samples of Bryansk region contaminated due to Chernobyl accident, J. Radioanal. Nucl. Chem., 247 (2001) 341 .

7) S. Yoshida, Y. Muramatsu, K. Tagami, S. Uchida, Concentrations of lanthanide elements, $T h$ and $U$ in 77 Japanese surface soils, Environ. International, 24 (1998) 275.

8) United Nations Scientific Committee on the Effects of Atomic Radiation, Sources and Effects of Ionizing Radiation, UNSCEAR 2000 Report to the General Assembly with Scientific Annexes, Vol. I Sources, 2000, United Nations, New York.

9) S. Uchida, K. Tagami, I. Hirai, Soil to plant transfer factors of stable elements and naturally occurring radionuclides (1) Upland field crops collected in Japan, J. Nucl. Sci. Technol., 44 (2007) 628 .

10) K. H. Wedepohl, The composition of the continental crust, Geochim. Cosmochim. Acta, 59 (1995) 1217.

11) A. Masuda, N. Nakamura, T. Tanaka, Fine structures of mutually normalized rare-earth patterns of chondrites, 37 (1973) 239. 